\title{
Strategy for Efficient Importing of NAD Analogs
}

\section{Lei Wang, ${ }^{\mathrm{a}}$ and Dayu $\mathrm{Yu}^{\mathrm{a}^{*}}$}

a School of Chemical Engineering, Northeast Electric Power University, Jilin 132012, China

E-mail: yudy@neepu.edu.cn

\begin{abstract}
It is difficult to study and manipulate the functions of NAD(P). NAD analogs can enhance our ability to understand signaling pathways mediated by NAD. But the application is limited. By constructing an efficient importing system will stimulate developing and screening of functional analogs.
\end{abstract}




\section{Introduction}

Recently two NAD manipulation strategies were developed to transport NAD directly across the cytoplasmic membrane, one was transporting the cofactor by NAD transporter, another was making cells permeable for the cofactors by proper treatment with certain organic solvent $[2,5,6]$. The NAD transporter could adjust intracellular NAD level in a wide range and the permeabilized cells realized high product concentration with high cofactor total turnover number [6,7]. Since NAD was added directly by the two strategies, the degradation characters of NAD should be considered for more efficient and precise manipulation.

To improve the efficacy of redox biocatalysts, it is essential to maintain the stability of nicotinamide cofactors, for which it is attractive to block degradation pathways for $N A D(H)$. While the biosynthesis of $\mathrm{NAD}(\mathrm{H})$ has been well studied, it is less understood how $\mathrm{NAD}(\mathrm{H})$ are degraded. In E. coli, only cytoplasmic NudC has been known as $\mathrm{NAD}(\mathrm{H})$ pyrophosphatase, which hydrolyzes NAD to nicotinamide mononucleotide (NMN) and adenosine monophosphate (AMP). NudC had low catalytic efficiencies for NADH $\left(0.03 \mu \mathrm{M}^{-1}\right.$ $\left.\mathrm{s}^{-1}\right)$ and NAD $\left(2.9 \times 10^{-4} \mu \mathrm{M}^{-1} \mathrm{~s}^{-1}\right)[8]$.

As NAD was impermeable, its metabolism could be studied as intracellular metabolism and extracellular metabolism respectively[8]. Study and compare intra- and extracellular metabolism of NAD might help improving NAD manipulation strategies and revealing how $E$. coli maintained its cofactor pool. Most reported NAD pyrophosphatases localized outside the cytoplasm[9]. Among the prokaryotic NAD pyrophosphatases, NadN from Haemophilus influenzae localized outside the cytoplasm and had two activities: it hydrolyzes NAD to NMN and AMP by NAD pyrophosphatase activity, then NMN and AMP are hydrolyzed to NR and Ado respectively by 5 '-nucleotidase activity[10].

In this report we demonstrated that UshA was a major periplasmic enzyme for NAD degradation in $E$. coli. By constructing an efficient importing system will stimulate developing and screening of functional analogs.

\section{Materials and methods}

\subsection{Regents and strains}

EasyPfu DNA polymerase was from TransGen Biotech (Beijing, China). PrimeSTAR HS DNA polymerase and DpnI were from TaKaRa (Dalian, China). All the primers were synthesized by Invitrogen. All reagents and enzyme substrates were from Bonuo (Dalian, China). Yeast ADH II was from Sigma. NMN was prepared as reported previously [10].

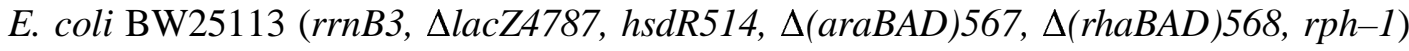
and its ushA deletion mutant E. coli JW0469 (BW25113/ushA::kan) was obtained from the Coli Genetic Stock Center [11]. E. coli WL001 was constructed by transformation of E. coli JW0469 with the UshA expression plasmid pA-ushA.

\subsection{NAD degradation activity of whole cells}

E. coli BW25113 and JW0469 cells were grown aerobically at $37{ }^{\circ} \mathrm{C}, 200 \mathrm{rpm}$ overnight in LB liquid medium (10 g tryptone, $5 \mathrm{~g}$ yeast extract, $10 \mathrm{~g} \mathrm{NaCl}$ per liter). For JW0469 cells, $50 \mu \mathrm{g} / \mathrm{mL}$ kanamycin was applied in the medium. E. coli WL001 cells were prepared at $30{ }^{\circ} \mathrm{C}$, $200 \mathrm{rpm}$ for $36 \mathrm{~h}$ in LB liquid medium supplemented with $100 \mu \mathrm{g} / \mathrm{mL}$ ampicillin and $1 \mathrm{mM}$ isopropyl thiogalactoside (IPTG).

The cells were harvested by centrifugation at $2000 \times \mathrm{g}$ for 6 min at $4{ }^{\circ} \mathrm{C}$, washed twice and suspended with $50 \mathrm{mM}$ Tris- $\mathrm{Cl}(\mathrm{pH} 7.5)$ to an optical density at $600 \mathrm{~nm}\left(\mathrm{OD}_{600 \mathrm{~nm}}\right)$ of 22 , 
which is approximately $7.3 \mathrm{~g}$ cell dry weight per liter $\left(\mathrm{g}_{\mathrm{CDw}} / \mathrm{L}\right)$ [2]. The cells were stored at $-80{ }^{\circ} \mathrm{C}$ before use.

NAD degradation activity of whole cells was assayed by measuring extracellular NAD concentration drop discontinuously. The reactions were carried out in the presence of $50 \mathrm{mM}$ Tris-Cl (pH 7.5), $1 \mathrm{mM} \mathrm{NAD,} 50 \mathrm{mM} \mathrm{MgCl}_{2}$, and $3.7 \mathrm{~g}_{\mathrm{CDW}} / \mathrm{L}$ E. coli BW25113 or JW0469 cells. E. coli WL001 samples were assayed at a final concentration of $53 \mathrm{mg}_{\mathrm{CDW}} / \mathrm{L}$.

The mixture was incubated at $37^{\circ} \mathrm{C}$ for $30 \mathrm{~min}$ and quenched by adding 0.1 volume of 2 $\mathrm{M} \mathrm{HCl}$ with further incubation at $50{ }^{\circ} \mathrm{C}$ for $10 \mathrm{~min}$. The mixtures were neutralized by equal volume of $0.1 \mathrm{M} \mathrm{NaOH}$, centrifuged at $12,000 \times g$ for $10 \mathrm{~min}$, and the supernatants were transferred to new tubes, stored at $-20^{\circ} \mathrm{C}$ before NAD concentration analysis.

NAD concentration were determined by cofactor recycling assay [6]. One unit of NAD degradation activity ( $1 \mathrm{U}$ ) was defined as hydrolyzing $1 \mathrm{nmol}$ NAD per hour.

\subsection{Thin layer chromatography (TLC) analysis}

Enzymatic products of UshA were assayed by TLC on silica gel according to a previous procedure $[13,14]$. Reactions were done at $37^{\circ} \mathrm{C}$ for $2 \mathrm{~h}$ in $50 \mu \mathrm{L}$ of $50 \mathrm{mM}$ Tris- $\mathrm{Cl}(\mathrm{pH} 7.5)$ contained $5 \mathrm{mM} \mathrm{MgCl} 2,10 \mathrm{mM} \mathrm{NAD}, 0.1 \mathrm{mg} / \mathrm{mL}$ BSA and appropriate amounts of UshA. Reactions were terminated by adding $5 \mu \mathrm{L}$ of $2 \mathrm{M} \mathrm{HCl}$, and centrifuged at $12,000 \times g$ for 10 min. Spotted $1.5 \mu \mathrm{L}$ of samples onto TLC plates, developed in a water/acetic acid /n-butanol (5: 3: 12; vol/vol/vol) mixture, and visualized under UV at $254 \mathrm{~nm}$.

\subsection{Stability of NAD supplied to permeabilized cell}

Permeabilized cells of BW25113 and JW0469 were prepared according to a previous process [5]. Briefly, frozen E. coli cells were thawed in a water bath at room temperature for $10 \mathrm{~min}$, added EDTA to $5 \mathrm{mM}$ and toluene to $1 \%$ (vol/vol), and incubated at $200 \mathrm{rpm}, 30{ }^{\circ} \mathrm{C}$ for $30 \mathrm{~min}$ and then at $4{ }^{\circ} \mathrm{C}$ for $1 \mathrm{~h}$. Cells were recovered by centrifugation at $2000 \times \mathrm{g}$ for 6 min, washed twice and suspended with Tris- $\mathrm{Cl}$ (50 mM, pH 7.5). Permeabilized cells were used immediately after preparation.

To determine the half-life time of exogenous NAD in the presence of permeabilized cells, a reaction mixture with $1 \mathrm{mM} \mathrm{NAD}, 50 \mathrm{mM} \mathrm{MgCl}_{2}$, and $3.7 \mathrm{~g}_{\mathrm{CDW}} / \mathrm{L}$ permeabilized cells were incubated at $37^{\circ} \mathrm{C}, \mathrm{pH} 7.5$. Aliquots of $90 \mu \mathrm{L}$ of reaction mixture were taken at $0 \mathrm{~h}, 0.5$ h, $1 \mathrm{~h}, 1.5 \mathrm{~h}, 2 \mathrm{~h}, 3 \mathrm{~h}$ and $4 \mathrm{~h}$, and NAD concentration was determined.

Half-life time of exogenous NAD was calculated according to the equation: $\log \mathrm{N}_{\mathrm{t}}=$ $\log \mathrm{N}_{0}-(\log 2 / \mathrm{T}) \times \mathrm{t}$, where $\mathrm{N}_{0}$ is the initial NAD concentration $(1 \mathrm{mM}), \mathrm{N}_{\mathrm{t}}$ is the observed NAD concentration at time $t, T$ is the half-life time of exogenous NAD.

\section{Results and discussions}

Degradation of extracellular NAD by $E$. coli cells during whole-cell biocatalysis has been noted recently $[5,7]$. This NAD degradation activity should be associated with enzyme outside the cytoplasmic membrane, but no such enzyme has been clearly described in the literature. Because the periplasmic enzyme NadN from Haemophilus influenzae had good NAD degradation activity [13], we did sequence alignment and found UshA of E. coli shared 29\% sequence identity with NadN. Both $\mathrm{NadN}$ and UshA have an N-terminal metallophosphatase domain and a C-terminal nucleotidase domain [16]. Interestingly, a previous study found that cell lysates of an E. coli BL21 cells transformed with the ushA gene expressing plasmid had high hydrolytic activities over a broad spectrum of substrates, such as 
AMP, ADP, ATP, CMP and CDP, and trace degrading activity for $\mathrm{NAD}(\mathrm{H})$ as well as a number of pyrophosphates, but detailed data remained unavailable [9]. We suspected UshA as a candidate periplasmic enzyme responded to NAD degradation.

To demonstrate the function of UshA, we constructed an UshA overexpression strain $E$. coli WL001. The whole-cell NAD degradation activities of WL001, the wild type strain BW25113 and the ushA gene deletion strain JW0469 were assayed, and specific activities were 20,000, 199 and $60 \mathrm{U} / \mathrm{mg}_{\mathrm{CDW}}$, respectively. UshA expression in the three strains was analyzed by SDS-PAGE, a noticeable expression decrease at the molecular weight of $59 \mathrm{kDa}$ was observed in JW0469 compared to BW25113, while UshA was highly overexpressed in WL001 upon induction (Fig. 1). The results confirmed the hypothesis that UshA has a major role in the degradation of extracellular NAD.

To further study the activity of UshA, we purified recombinant UshA from WL001 by His $_{6}$-tag affinity chromatography to near homogeneity (Fig. 1). Analysis of UshA-catalyzed NAD degradation reaction by TLC clearly indicated that NAD was consumed, but there was apparently no accumulation of either AMP or NMN. Instead, the presence of NmR and Ado was evident for those lanes with complete consumption of NAD (Fig. 2A). It was known that NAD can be hydrolyzed to form NMN and AMP by NAD pyrophosphatase [8]. However, TLC results suggested that UshA catalyzed further hydrolysis of NMN and AMP into NmR and Ado, respectively, by 5'-nucleotidase activity (Fig. 2B). Moreover, it seemed that UshA had much higher 5'-nucleotidase activity than pyrophosphatase activity, as both AMP and NMN were not accumulated during the reaction. Therefore, UshA is a promiscuous hydrolytic enzyme which is reminiscent of NadN from $H$. influenzae [13].

Kinetic parameters of UshA catalysis were determined using NAD, NADH, AMP and NMN, respectively, as substrate (Table 1). While $K_{m}$ values were close for all of these substrates, $k_{c a t}$ values for AMP and NMN were orders of magnitude higher than those for $\mathrm{NAD}(\mathrm{H})$. The $k_{c a t} / K_{m}$ values for AMP and NMN were roughly two orders of magnitude higher than those for $\mathrm{NAD}(\mathrm{H})$, indicating that UshA had substantially higher catalytic efficiency for phosphate hydrolysis than pyrophosphate hydrolysis. These data were consistent with results of TLC analysis.

It should point out that the recombinant UshA had the highest NAD pyrophosphatase activity compared to other enzymes collected by BRENDA [17]. The $K_{m}$ values for NAD (5.3 $\mu \mathrm{M})$ and NADH $(7.0 \mu \mathrm{M})$ of UshA were substantially lower, indicating UshA has much stronger binding affinity toward $\mathrm{NAD}(\mathrm{H})$ compared to other pyrophosphatases. For NADH degradation, the most efficient pyrophosphatase was $E$. coli NudC with a $k_{c a} / K_{m}$ value of 0.03 $\mu \mathrm{M}^{-1} \mathrm{~s}^{-1}$ [8], which was considerably lower than that of UshA $\left(1.4 \mu \mathrm{M}^{-1} \mathrm{~s}^{-1}\right)$. Therefore, albeit UshA has higher 5'-nucleotidase activity, it remains the most efficient $\mathrm{NAD}(\mathrm{H})$ pyrophosphatase known so far.

We next checked extracellular NAD stability under conditions similar to whole-cell biocatalysis. When NAD was incubated in the presence of permeabilized E. coli JW0469 or BW25113 cells, NAD concentration dropped continuously (Fig. 3). Based on these data, the half-life time of NAD in the presence of JW0469 cells was 3.78 $\pm 0.12 \mathrm{~h}$, which was 3.1-fold of that $(1.21 \pm 0.08 \mathrm{~h})$ of BW25113 cells. This was consistent with the fact that JW0469 whole 
cells had only about $30 \%$ NAD degradation activity of that of the wild-type strain (vide ante). These data clearly demonstrated that the deletion of the ushA gene improved extracellular NAD stability, which should be beneficial to cofactor-dependent whole-cell biocatalysts. We noticed that the deletion of the $u s h A$ gene only reduced NAD degradation activity by $70 \%$, indicating that there were additional gene(s) responsible for periplasmic NAD degradation. Identification of these gene(s) may be interesting for the construction of E. coli strains with minimal NAD degradation activity. We recently succeeded in devising E. coli NAD-auxotrophic mutants and expanding the dynamic ranges of cellular NAD levels from 0.04- to 9.6-fold of that of wild type cells [6]. If genes responsible for NAD degradation were removed, our capacity for $\mathrm{NAD}(\mathrm{H})$ manipulation should reach a new stage, because exogenous $\mathrm{NAD}(\mathrm{H})$ could be applied for more robust and precise control on cofactor availability for biocatalysts.

The deletion of the ushA gene also led to improved cell growth. Under identical culture conditions in M9 medium JW0469 and BW25113 cells reached a cell density of $\mathrm{OD}_{600}=3.8 \pm 0.03$ and $\mathrm{OD}_{600}=3.1 \pm 0.06$, respectively, after $10 \mathrm{~h}$ (Fig. 4), indicating the deletion of the $u s h A$ gene promoted cell growth by $24 \%$.

Our results and previous data [9] indicated that E. coli UshA was a promiscuous (pyro)phosphatase enzyme and that its NAD pyrophosphatase activity was noticeably lower than 5'-nucleotidase activity. This activity profile may be advantageous for cells to facilitate utilization of extracellular nutrients under various environments. For biotechnological application such as whole-cell biocatalysis, however, the removal of UshA could improve extracellular NAD stability and cell growth.

\section{Conclusion}

This work demonstrated that UshA was a major periplasmic enzyme for NAD degradation in E. coli. The deletion of the $u s h A$ gene reduced NAD degradation activity by $70 \%$ and promoted cell growth. Recombinant UshA showed high $\mathrm{NAD}(\mathrm{H})$ pyrophosphatase activity, which significantly enriched our understanding on NAD metabolism. These results should facilitate many applications including designing more robust redox biocatalysts.

\section{Acknowledgements}

This work was supported by the National Basic Research and Development Program of China (No. 2012CB721103) and the State Key Laboratory of Catalysis (R201306).

\section{References}

[1] Holm AK, Blank LM, Oldiges M, Schmid A, Solem C, Jensen PR, et al. Metabolic and transcriptional response to cofactor perturbations in Escherichia coli. J Biol Chem. 2010;285:17498-506.

[2] San KY, Bennett GN, Berrios-Rivera SJ, Vadali RV, Yang YT, Horton E, et al. Metabolic Engineering through Cofactor Manipulation and Its Effects on Metabolic Flux Redistribution in Escherichia coli. Metab Eng. 2002;4:182-92.

[3] Berrios-Rivera SJ, Bennett GN, San KY. The effect of increasing NADH availability on the redistribution of metabolic fluxes in Escherichia coli chemostat cultures. Metab Eng. 2002;4:230-7.

[4] Zhang J, Witholt B, Li Z. Coupling of permeabilized microorganisms for efficient enantioselective reduction of ketone with cofactor recycling. Chem Commun (Camb). 2006:398-400. 
[5] Zhang W, O'Connor K, Wang DIC, Li Z. Bioreduction with Efficient Recycling of NADPH by Coupled Permeabilized Microorganisms. Appl Environ Microbiol. 2009;75:687-94.

[6] Zhou YJ, Wang L, Yang F, Lin X, Zhang SF, Zhao ZBK. Determining the extremes of the cellular $\mathrm{NAD}(\mathrm{H})$ level by using an Escherichia coli NAD+-auxotrophic mutant. Appl Environ Microbiol. 2011;77:6133-40.

[7] Zhou YJ, Yang W, Wang L, Zhu Z, Zhang S, Zhao ZK. Engineering NAD+ availability for Escherichia coli whole-cell biocatalysis: a case study for dihydroxyacetone production. Microb Cell Fact. 2013;12:103.

[8] Frick DN, Bessman MJ. Cloning, purification, and properties of a novel NADH pyrophosphatase. Evidence for a nucleotide pyrophosphatase catalytic domain in MutT-like enzymes. J Biol Chem. 1995;270:1529-34.

[9] Alves-Pereira I, Canales J, Cabezas A, Cordero PM, Costas MJ, Cameselle JC. CDP-alcohol hydrolase, a very efficient activity of the 5'-nucleotidase/UDP-sugar hydrolase encoded by the ushA gene of Yersinia intermedia and Escherichia coli. J Bacteriol. 2008;190:6153-61.

[10] Ji D, Wang L, Hou S, Liu W, Wang J, Wang Q, et al. Creation of bioorthogonal redox systems depending on nicotinamide flucytosine dinucleotide. J Am Chem Soc. 2011;133:20857-62.

[11] Baba T, Ara T, Hasegawa M, Takai Y, Okumura Y, Baba M, et al. Construction of Escherichia coli K-12 in-frame, single-gene knockout mutants: the Keio collection. Mol Syst Biol. 2006;2.

[12] van den Ent F, Lowe J. RF cloning: A restriction-free method for inserting target genes into plasmids. J Biochem Bioph Methods. 2006;67:67-74.

[13] Kemmer G, Reilly TJ, Schmidt-Brauns J, Zlotnik GW, Green BA, Fiske MJ, et al. NadN and e (P4) are essential for utilization of NAD and nicotinamide mononucleotide but not nicotinamide riboside in Haemophilus influenzae. J Bacteriol. 2001;183:3974-81.

[14] Lee KS, Song SB, Kim KE, Kim YH, Kim SK, Kho BH, et al. Cloning and characterization of the UDP-sugar hydrolase gene (ushA) of Enterobacter aerogenes IFO 12010. Biochem Biophys Res Commun. 2000;269:526-31.

[15] Baykov AA, Evtushenko OA, Avaeva SM. A malachite green procedure for orthophosphate determination and its use in alkaline phosphatase-based enzyme immunoassay. Anal Biochem. 1988;171:266-70.

[16] Marchler-Bauer A, Lu S, Anderson JB, Chitsaz F, Derbyshire MK, DeWeese-Scott C, et al. CDD: a Conserved Domain Database for the functional annotation of proteins. Nucleic Acids Res. 2011;39:D225-9.

[17] Schomburg I, Chang A, Placzek S, Sohngen C, Rother M, Lang M, et al. BRENDA in 2013: integrated reactions, kinetic data, enzyme function data, improved disease classification: new options and contents in BRENDA. Nucleic Acids Res. 2013;41:D764-72.

[18] Wagner R, Feth F, Wagner KG. The Pyridine-Nucleotide Cycle in Tobacco - Enzyme-Activities for the Recycling of Nad. Planta. 1986;167:226-32. 


\section{Tables}

Table 1. Kinetic parameters of UshA and other NAD pyrophosphatases.

\begin{tabular}{|c|c|c|c|c|c|}
\hline Substrate & $\begin{array}{l}K_{m} \\
(\mu \mathrm{M})\end{array}$ & $\begin{array}{l}k_{\text {cat }} \\
\left(\mathrm{s}^{-1}\right)\end{array}$ & $\begin{array}{l}k_{\text {cat }} / K_{m} \\
\left(\mu \mathrm{M}^{-1} \mathrm{~s}^{-1}\right)\end{array}$ & Enzyme $^{a}$ & $\begin{array}{l}\text { Reference or } \\
\text { resource }\end{array}$ \\
\hline AMP & $1.2 \pm 0.1$ & $405 \pm 4$ & 334 & UshA & This study \\
\hline AMP & 1.8 & 372 & 210 & UshA & {$[9]^{b}$} \\
\hline AMP & 1090 & - & - & $\mathrm{NadN}$ & {$[13]$} \\
\hline NMN & $11.1 \pm 1.3$ & $1492 \pm 31$ & 135 & UshA & This study \\
\hline NMN & 1260 & - & - & $\mathrm{NadN}$ & [13] \\
\hline NAD & $5.3 \pm 0.6$ & $19.3 \pm 0.9$ & 3.7 & UshA & This study \\
\hline NAD & 430 & - & - & $\mathrm{NadN}$ & {$[13]$} \\
\hline NAD & $5100 \pm 500$ & $1.5 \pm 0.1$ & $2.9 \times 10^{-4}$ & NudC & [8] \\
\hline NAD & 110 & - & - & $\mathrm{NudC}_{\mathrm{Nt}}$ & [18] \\
\hline NADH & $7.0 \pm 0.8$ & $10.0 \pm 0.2$ & 1.4 & UshA & This study \\
\hline $\mathrm{NADH}$ & $110 \pm 20$ & $3.8 \pm 0.2$ & 0.03 & NudC & {$[8]$} \\
\hline
\end{tabular}

${ }^{a}$ UshA: recombinant E. coli UshA; NadN: recombinant $H$. influenzae NadN. NudC: recombinant E. coli NudC (synonym of $\mathrm{YjaD}$ ). $\mathrm{NudC}_{\mathrm{Nt}}$ : wild-type NudC from Nicotiana tabacum root.

${ }^{b}$ The reaction condition was the same as this study, with $\mathrm{Mg}^{2+}$ as the activating cation. 


\section{Figures}

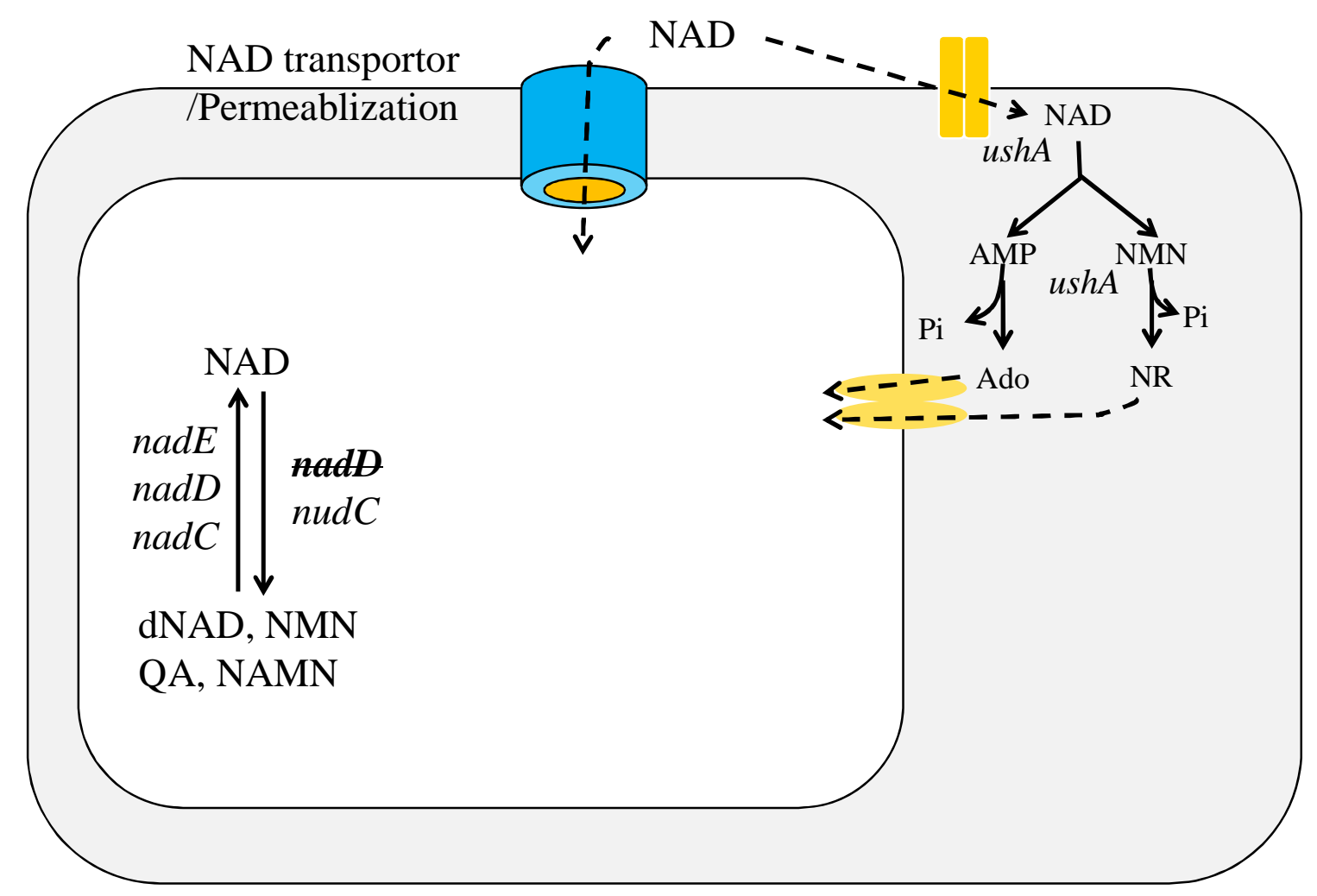

Figure 1. NAD degradation activity of E. coli BW25113 and its ushA::kan mutant. 


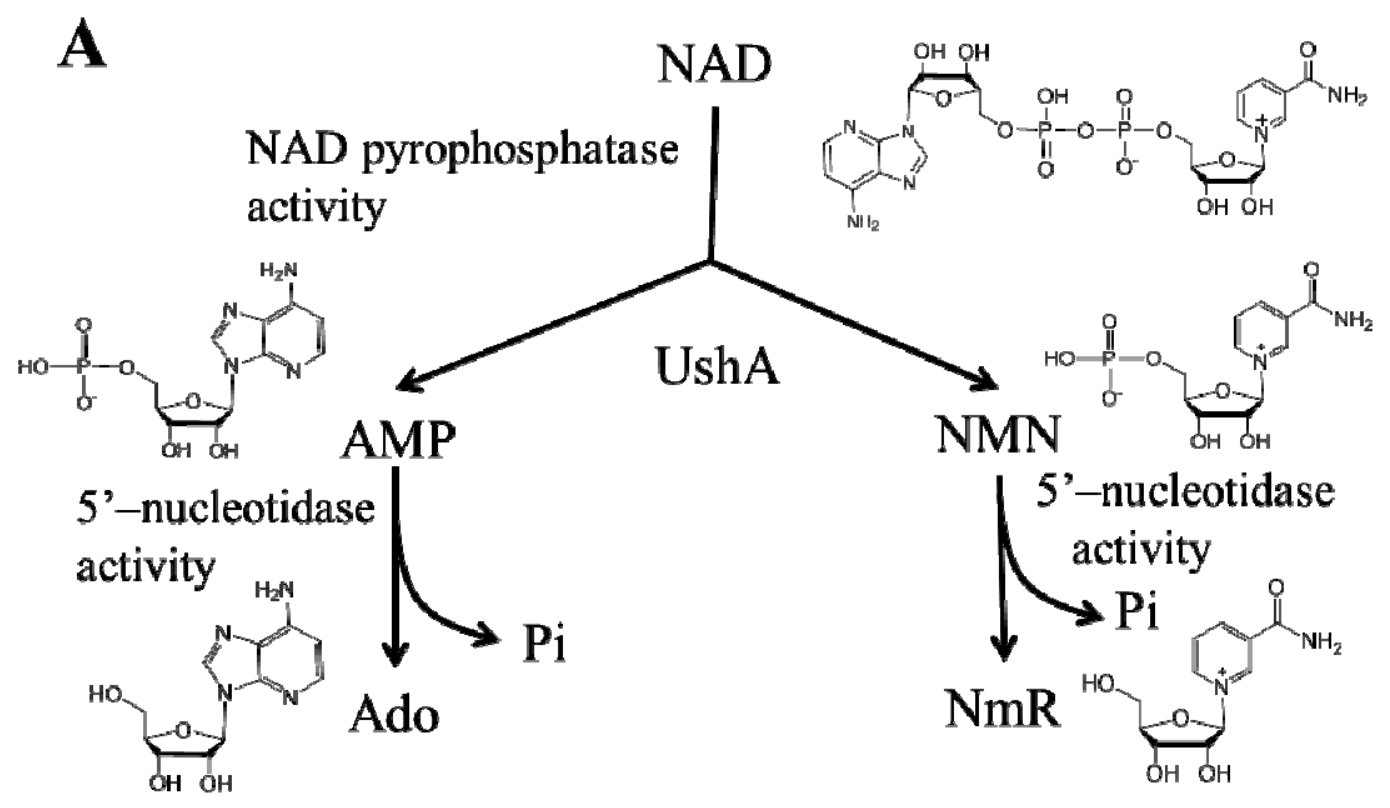

Figure 2. NAD degradation activity of recombinant UshA. Proposed NAD degradation paths by NadN like activity of UshA. Abbreviations: NAD, nicotinamide adenine dinucleotide; AMP, adenosine monophosphate; Ado, adenosine; NMN, nicotinamide mononucleotide; NmR, nicotinamide riboside. 


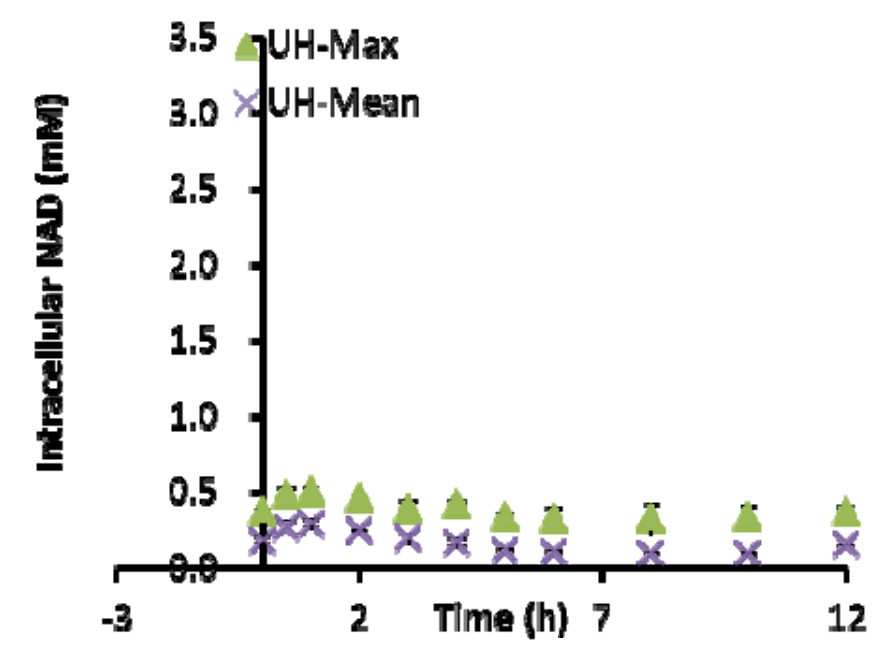

Figure 3. Time course of NAD degradation in the presence of permeabilized $E$. coli cells. Assays were initiated with $1 \mathrm{mM}$ of $\mathrm{NAD}$ at $37^{\circ} \mathrm{C}, \mathrm{pH} 7.5$. The data represent the averages standard deviations of three independent experiments. 